\title{
Methodological Research on Architecture of Cloud Service Models in Cloud Computing
}

\author{
Diwakar Ramanuj Tripathi
}

\begin{abstract}
Cloud computing is the most recent association in speaking to computing resources as an assistance. It addresses a move away from figuring as a thing that is gained, to computing as a help that is given to clients over the web from colossal scale data focuses - or "clouds". While cloud computing is expanding making acclaim in the IT business, the academic world appeared to fall behind the speedy movements in this field. In this paper, we investigate cloud building and differences cloud figuring and framework handling. We also address the characteristics and uses of a couple of surely understood cloud computing stages. In this paper, we discuss about the architecture of cloud computing models for which we perceived a couple of troubles from the cloud figuring gathering point of view what's more, we additionally highlighted the cloud interoperability issue that preferences broad future scope \& progress.
\end{abstract}

Key words: Cloud computing, cloud technologies, computing resources, architecture.

\section{INTRODUCTION}

Cloud computing is a method for engaging across-the-board, on-demand and useful network access to a standard pool of configurable computer properties (e.g., platforms, servers, data, software and associations) that can be distributed and discharged efficiently with trivial association commitment or expert relationship correspondence". Cloud computing can be seen as a framework of organizations engaged in providing versatile, QoS-guaranteed on-demand benefits that can be accessed over the Internet.

Cloud computing is a new way forward completed. It is the advancement of parallel computing, passed on to computing framework computing, and is the blend and improvement of virtualization, utility computing, software-as - a-service (SaaS), As-a-service infrastructure (IaaS) and as-a-service platform (PaaS). Cloud is a

representation of the web as a space in which computing has been pre-established and operates as an aid; content, operating systems, software, compilation and preparation for sharing resides on the web suit. Cloud computing is a Pay-per-Use-On-Demand environment for consumers that can kindly find good speed assets over the Internet. Where the IT assets touch system, folder, putting away, program, affiliation, etc. and can be carried on with a lot more realistic and straightforward way and less bureaucratic, as well as partnerships with vendors to organizations. Cloud computing would greatly enhance IT resource openness and have different focal points over other computer structures.

Revised Manuscript Received on March 11, 2020.

* Correspondence Author

Diwakar Ramanuj Tripathi*, Information Technology Consultant, Nagpur

(c) The Authors. Published by Blue Eyes Intelligence Engineering and Sciences Publication (BEIESP). This is an open access article under the CC BY-NC-ND license (http://creativecommons.org/licenses/by-nc-nd/4.0/)

Using Pay-per-Use-On-Demand mode, customers can use the IT foundation; this would benefit from an extra the cost of buying the physical assets that may be unfilled.

\subsection{Architectural Components}

Data infrastructure systems are typically separated from SaaS, PaaS, and IaaS that a certain data system has shown. Incorporating additional structure into the administration version stacks is necessary.

\section{A. Software as a Service (SaaS)}

Cloud purchasers release the uses of theirs in an empowering state, which may be gotten to through devices from different clients (for instance Internet application, PDA, along with therefore on.) by program clients. Cloud shoppers don't have authority over the cloud establishment that a great part of the time utilizes multi-inhabitance framework building, to be explicit, striking cloud purchasers' applications are created in a solitary authentic condition in the SaaS cloud to accomplish economies of progress and scale concerning upkeep, calamity recovery, accessibility, security, and speed. Events of SaaS join SalesForce.com, Google Mail, Google Docs, in this manner forward.

\section{B. Platform as a Service (PaaS)}

Cloud customers release the uses of theirs in an empowering situation, which may be gotten to through structures from a variety of customers (for example Internet program, PDA, and so forth.) by application clients. Cloud shoppers don't have authority over the cloud establishment that a significant part of the time utilizes multi-inhabitance framework designing, to be explicit, surprising cloud customers' applications are made in a solitary authentic condition in the SaaS cloud to achieve economies of scale and progression regarding speed, security, openness, disaster recuperation and upkeep. Occurrences of SaaS join SalesForce.com, Google Mail, Google Docs, in this way forward.

\section{Infrastructure as a Service (IaaS)}

Cloud clients undeniably utilize information technology systems (managing, limit, structures along with other focal computing resources) gave in the IaaS cloud. Virtualization is often employed in IaaS cloud and so as to fuse/self destruct bodily materials in an exceptionally designated way to satisfy making or perhaps contracting advantage need from cloud purchasers. The essential process of virtualization is usually to set up free virtual machines (VM) which are isolated from the pivotal gear as well as various VMs. Notice this method isn't proportionate to the multi inhabitance version, which plans to alter the application programming designing with the target that various cases (from different cloud shoppers) can run on a particular application (for example a comparable strategy for thinking machine).

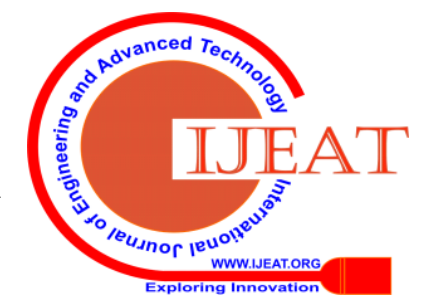




\section{Methodological Research on Architecture of Cloud Service Models in Cloud Computing}

An instance of IaaS is actuallyAmazon's EC2.

\section{Data as a Service (DaaS)}

The improvement of virtualized collecting on request changes into an alternate Cloud administration - data storing administration. Notice that DaaS could be viewed as a one of a kind sort IaaS. The inspiration is the fact that on premise endeavor repository structures are regularly connected in a prohibitive specific price in submitted server, programming award, post transport administrations and in house IT upkeep. DaaS empowers buyers to pay for what they're truly utilizing instead of the site permit for the whole database. Despite standard accumulating interfaces, for example, RDBMS and record structures, some DaaS responsibilities give table-style reflections which are suggested to scale out to store as well as recoup a high information inside an inconceivably compacted timeframe, regularly extremely huge, an excessive amount of costly or illogically delayed for most business RDBMS to change in accordance with. Examples of this kind of DaaS unite Apache HBase, Go

BigTable, and Amazon S3, and so on.

\section{LITERATURE REVIEW}

Tao Zhang et. al. (2019) Cloud computing is acclimating various huge changes with individuals' way of life and working model beginning late for its innumerable favorable circumstances. No matter, the blend of different prospective cloud customers, and a noteworthy prevention for its no matter how you look at it applications. Last but not least, we provided some security techniques coming from the use of view of headway, action and security occasion reaction to diminish the run of the mill security issues of cloud computing.

Anurag Jain et. al. (2018) Cloud computing is yet another computational style that is basically founded on cross area computing. Cloud computing are usually portrayed as a computing surroundings anywhere computing requirements by one gathering are actually every again and now redistributed to an alternative gathering and when might need be emerge to make use of the computing power or maybe materials as messages or information, they are going to get to them by means of web. This particular paper is actually for anyone who'll have starting late perceived with respect to cloud computing and requires to obtain a handle on a great deal of in respect to cloud computing.

Ting Chen et. al.(2012) As another framework, cloud computing has a quick improvement as of late. Regardless, the security issues have made unfathomable impacts the improvement and progression of cloud computing, the noteworthiness and criticalness has not to be overlooked. This paper presents cloud computing and security condition, mulls over the essential protection issues of cloud computing protection framework which can adequately manage these security issues, and shows out that just handle the security issues, cloud computing can unendingly broadened, and the application will be progressively more for the most part.

Asniar Tj and Reza Budiawan (2016) Cloud computing research is another model in streamed computing, where individuals have made assistance and SOA (Service Oriented Architecture) based application. This improvement is fantastically valuable to be acknowledged, especially for forefront guidance. This investigation is reviewed the need and credibility for the fittingness of cloud computing in front line preparing by then propose the model of cloud computing administration in bleeding edge guidance in Indonesia that can be finished so as to help academic activities. Composing study is utilized as the investigation hypothesis to get a proposed model of cloud computing in front line preparing. Finally, SaaS and IaaS are cloud computing administration that proposed to be executed in front line preparing in Indonesia and cloud cream is the administration model that can be embraced.

\subsection{Deployment Models}

The movement of virtualized accumulating on needs changes into its own Cloud administration - data amassing administration. Notice which DaaS might be viewed as an exceptional sort IaaS The inspiration is actually the path that on guarantee adventure database methods are usually connected in a prohibitive starting price in submitted server, post -transport administrations, programming license, and in house IT support. DaaS empowers purchasers to cover what they're genuinely using as opposed to the site permit for the entire database. Close by standard accumulating interfaces including RDBMS just as record

strategies, some Daas responsibilities supply table like thoughts that are made to scale out to store what's more recover a huge proportion of information in just an amazingly compacted time span, by and large too huge, unnecessarily costly or perhaps absurdly postponed for some business RDBMS to oversee.

\section{- Private cloud:}

The cloud foundation is worked totally inside affiliation, and besides dealt with by the social affair or potentially a pariah in any case if it's masterminded introduction and off explanation. The motivation to course of action an individual cloud inside an association has several regions. For one thing, to grow and improve the utilization of current in home resources then, security concerns as information security \& trust Private Cloud a possibility for a lot of firms. Third, information move cost [eight] from neighborhood IT system to a Public Cloud continues being truly tremendous. Fourth, affiliations reliably need boundless oversight over essential activities which live behind the firewalls of theirs. Last, scholastics routinely build private cloud for study and training purposes. In any case, singular clouds have different weights. For instance, on premises IT - instead of a pariah cloud provider - is subject for controlling the individual cloud. Thus, private cloud game plans offer definitely the comparable staffing, the administrators, upkeep and capital uses as standard data office ownership. Extra individual cloud costs are virtualization, cloud the officials gadgets and cloud programming program.

\section{- Community cloud:}

Community clouds are actually a cross breed sort of private clouds collected as well as worked especially for a certain social event. 
These public orders have essentially equivalent to cloud necessities and a conclusive goal of theirs is working in show to achieve the business goals of theirs. Network clouds are ordinarily made for associations and affiliations doing investigation, applications, or joint endeavors, that incorporates a central cloud computing place for making, performing and controlling such exercises, paying little mind to the plan rented. Various affiliations together create and look at a comparable cloud system close by courses of action, characteristics, necessities, and issues. The cloud network structures into a level of lion's share rule balance and moreover cash related limit. The cloud establishment may be encouraged by a third assembling shipper or possibly inside among the associations.

\section{- Public cloud}

This' the training sort of existing Cloud computing course of action model Individuals all in all cloud is utilized by the normal people cloud. Customers in like manner as the cloud organization supplier have the full scale duty regarding open cloud with the case technique of its, costing, and advantage, regard, and besides charging model. A couple of most likely comprehended cloud administrations are open clouds including

Amazon EC2, Google

\section{AppEngine, S3, and Force.com.}

\section{- Hybrid cloud}

The cloud product is a mix of two or maybe conceivably much more clouds (private, collecting, or perhaps maybe open) which continue being exceptional components anyway are bound together by selective or regulated development which grants information and software transportability (e.g., cloud impacting for load modifying between clouds). Associations make use of the hybrid cloud sort to have the alternative to improve the information of theirs to extend the middle capacities of theirs by margining perpetually periphery business limits upon the cloud while supervising concentration practices on premise through near and dear cloud. Blend cloud has improved the problems of business as well as furthermore cloud interoperability that will in all likelihood be referenced in eventually fragments. Amazingly, AWS has as of late starting late uncovered an imaginative kind of sending unit - Virtual Private Cloud (VPC), a secure and reliable augmentation between an organization's current IT program and aside from the Amazon receptive cloud].

\section{PROPOSED METHODOLOGY}

\subsection{Well known Cloud Computing Platforms}

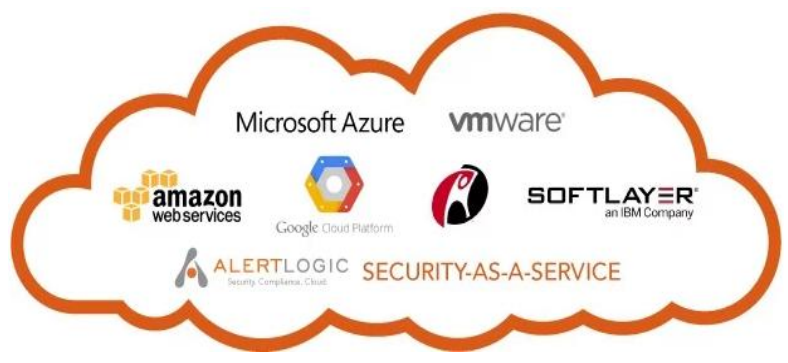

\section{A. Abicloud}

Abicloud is actually a cloud computing stage, It may be used to collect, arrange as well as supervise open similarly as private cloud in the homogeneous circumstances. Utilizing Abicloud, prospect could without quite a bit of a stretch and normally pass on what's more, control the server, putting away applications, virtual contraptions, plan, and structure, etc. The fundamental ability among Abicloud alongside other distributed computing stages is its staggering electronic organization point of confinement and the middle encapsulation mode of its. To utilize the Abicloud, client is able to wrap up assistance by in essence pulling a virtual computer with mouse. This is altogether less complicated and adaptable compared to some other cloud computing stages that deliver brand new administrations via bearing lines.

Abicloud may be used to pass on and execute private cloud likewise as cross breed cloud as evidenced by the cloud suppliers' mentioning and arrangement. It is able to in like fashion regulate EC2 as evidenced by the concepts of show. Additionally, use the Abicloud, a whole cloud arrange dependent on Abicloud could be squeezed as well as redeployed at various other Abicloud organize. This is a lot of solid for the difference in the workplace and will make the cloud sending process a lot less complex and flexible.

\section{B.Elastic Utility Computing Architecture for Linking Your Programs to Useful Systems}

Eucalyptus basically was used to make open source private cloud arrange. Eucalyptus is actually an adaptable computing system which may be used to interface the clients' activities to the obliging frameworks; it's an open source establishment utilizing packs or maybe workstation delivery of supple, utility, cloud computing along with a notable computing regular dependent on an assist level show which award clients lease program computing limit. Beginning at today, Eucalyptus is actually flawless with EC2 from Amazon, and might improve constantly various kinds of people with least change as well as development.

\section{C.Nimbus}

In fact, Aura is an open instrument set, and a cloud computing strategy that gives IaaS. It licenses customers to lease the basic computing condition from remote energy \& production through the virtual machine relationships. All these useful pieces will usually be classified in three types. Another category is customer-strengthened modules used to support a wide range of cloud users. To a large extent, setting customer module, cloud customer module, reference customer module, and EC2 customer module have a spot with this kind of section. The second kind of part is essentially cloud arrangement modules kept up by administration, giving a wide range of cloud administrations. This incorporates an administrator module, an information management framework for site governance, an EC2 WSDL platform and a remote interface module. The third type of section is the board module installation component that is commonly used to handle a wide range of physical resources on the cloud computing level, including board module job management, IaaS entry module, EC2 and other system arranging boost package, workspace pilot module, administrator module workspace advantage as well as workspace controller.

\section{E. Open Nebula}

Published By:

Blue Eyes Intelligence Engineering

Retrieval Number: D6723049420/2020@BEIESP

DOI: 10.35940/ijeat.D6723.049420

Journal Website: www.ijeat.org

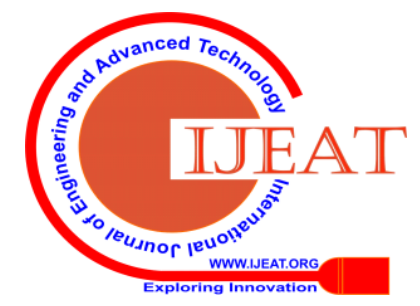




\section{Methodological Research on Architecture of Cloud Service Models in Cloud Computing}

Open Nebula is similarly a framework for open source cloud administration. It gives the client the ability to send and manage virtual machines on physical resources, and it can set the data focus of the client or social events to adapt virtual establishment that can normally change according to the distinction in the load of administration.

Table 1: The Comparison of Server Cloud Computing Platforms

\begin{tabular}{|l|l|l|l|l|}
\hline- & Abicloud & Eucalyptus & Nimbus & Open Nebula \\
\hline Cloud Character & Public/private & Public & Public & Private \\
\hline Scalability & Scalable & Scalable & Scalable & Dynamic, Scalable \\
\hline Clouds form & IaaS & IaaS & IaaS & IaaS \\
\hline Compatibility & Not support EC2 & $\begin{array}{l}\text { Support EC2, } \\
\text { S3 }\end{array}$ & Support EC2 & $\begin{array}{l}\text { Open, multi- } \\
\text { platform }\end{array}$ \\
\hline Deployment & Pack and redeploy & $\begin{array}{l}\text { Dynamical } \\
\text { deployment }\end{array}$ & $\begin{array}{l}\text { Dynamical } \\
\text { deployment }\end{array}$ & $\begin{array}{l}\text { Dynamical } \\
\text { deployment }\end{array}$ \\
\hline $\begin{array}{l}\text { Deployment } \\
\text { Manner }\end{array}$ & $\begin{array}{l}\text { Web interface } \\
\text { drags }\end{array}$ & Command line & $\begin{array}{l}\text { Command } \\
\text { line }\end{array}$ & Command line \\
\hline $\begin{array}{l}\text { Transplant- } \\
\text { ability }\end{array}$ & Easy & Common & Common & Common \\
\hline $\begin{array}{l}\text { VM support } \\
\text { Web interface }\end{array}$ & $\begin{array}{l}\text { Virtual Box, Xen, } \\
\text { VMware, VM }\end{array}$ & $\begin{array}{l}\text { Xen, VMware, } \\
\text { KVM }\end{array}$ & Xen & Xen, VMware \\
\hline $\begin{array}{l}\text { Structure } \\
\text { Reliability }\end{array}$ & $\begin{array}{l}\text { Opeb service } \\
\text { encapsulates cor }\end{array}$ & $\begin{array}{l}\text { EC2, WSDL, } \\
\text { WSRF }\end{array}$ & Xen, VMware \\
\hline $\begin{array}{l}\text { OS support } \\
\text { language }\end{array}$ & $\begin{array}{l}\text { Linux } \\
\text { python }\end{array}$ & - & $\begin{array}{l}\text { Lightweight } \\
\text { components }\end{array}$ & Module \\
\hline
\end{tabular}

\subsection{Applications}
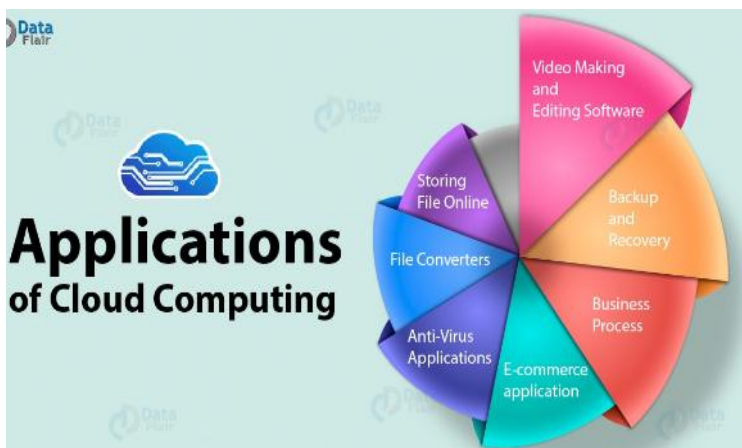

You will find a few of uses of cloud computing as pursues:

1) Cloud computing provides secure and dependable information storage focus.

2) Cloud computing is able to recognize information sharing among various types of gear.

3) The cloud provides almost infinite likelihood to clients to use the internet.

4) Cloud computing needn't bother with excellent gear for the client and it is easy to utilize.
3.3 Problems and challenges of Cloud Computing

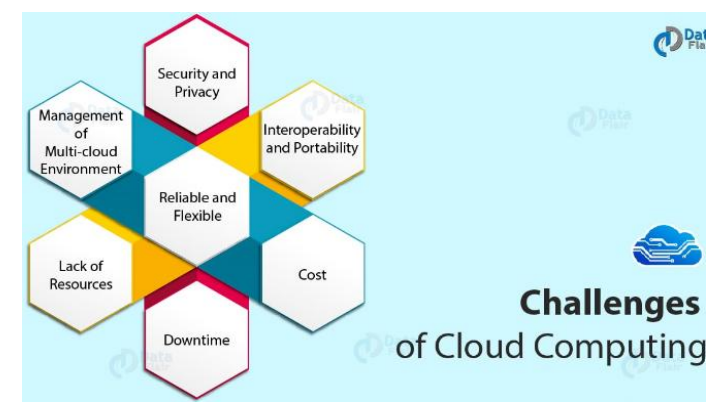

Progressively much more details on individuals \& organizations are put in the cloud; worries are starting to produce about precisely just how secure a circumstance it's? Problems of cloud computing is able to condense as seeks after:

\section{$>$ Privacy}

Cloud computing uses the virtual computing advancement, customers' near and dear information might be scattered in different virtual details believes rather compared to stay in the identical bodily devices on actual physical energy and this is able to set client's information concentrates

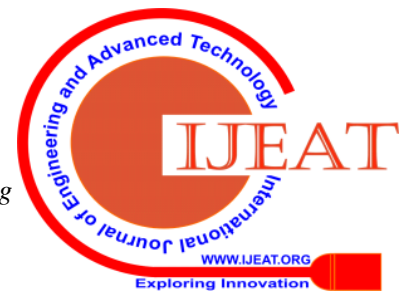


or maybe community affairs to adaptable virtual establishment which could thusly change in accordance with the distinction to the administration load. The vital separation of Open Nebula as well as glow is the fact that aura executes remote interface subject to WSRF or maybe EC2 through which prospect is able to process all security associated problems, while Open Nebula does not. Amenable Nebula is moreover an open as well as adaptable virtual system the board gadget, that can utilize to synchronize the limit, arrange and virtual methods and let customers dynamically mail advantages on the hovered establishment as evidenced by the job methods for remote cloud and information emphasis resources. By means of inside interfaces \& OpenNebula data focus condition, clients could without rather a good deal of a stretch pass on virtually any kinds of clouds. Region, clients may spill secured information when they're gotten the chance to cloud computing administrations. Aggressors can evaluate the essential job depend on the computing process set up together by the clients.

\section{$>$ Reliability}

The cloud servers similarly expertise excursions as well as log stick as the nearby server of ours.

\section{$>$ Legal Issues}

Stresses stay with security measures as well as distinction of specific totally through authoritative levels.

\section{$>$ Issues in Cloud Interoperability}

a) Intermediary Layer

Different continuous functions address the interoperability problem by giving a middle person level between the cloud shoppers as well as the cloud unequivocal resources.

\section{b) Open Standard}

Standardization has all the earmarks of being a not too bad response for tackle the interoperability problem. Nevertheless, as cloud computing merely starts removing, the interoperability matter hasn't showed up on the crushing strategy of considerable business cloud dealers.

\subsection{Issues on Cloud Adoption Perspective By IDC in 2008}

- Security

No ifs, ands or goals understood security issues, such as data calamity, phishing, botnet (running remotely on a machine scheme) existing affirmed hazards to the programming of an affiliation as well as information. The multi-residential design as well as the distributed device materials on cloud computing have proved new security problems, such as shared resources (hard circle, info, VM) Invites fantastic side-routes with a toxic advantage and a daily advantage on an equivalent body scanner. Furthermore, the "reputation fate sharing" problem will really damage the standing of various remarkable "inhabitants" of the Cloud who tragically share the computing materials because of their specific tenant-an infamous client with a criminal character.

\section{- Costing Model}

Shoppers in the cloud need to learn about the tradeoffs between calculating, communication and teamwork. Although shifting to the cloud will ultimately eliminate system costs, it increases the cost of interaction with data.

\section{- Security and Privacy Issue}

Due to the high simplicity of its existence, cloud computing is able to provide infinite storage resources on demand, which discards the critical criteria for cloud expert companies to schedule equipment provisioning. Different associations, such as Microsoft, Google, and Amazon, etc., are reviving their paces in building cloud computing and improving their administration to accommodate a much better proportion of customers.

With this article, we look at the protection as well as insurance issues that a proportion of organizations have provided back and forth movement cloud computing systems. As cloud computing proposes apps that the web and also the establishments (i.e., the gear as well as the structures programming in the information focus) that provide those administrations are disregarded as administrations.

\section{- Protection on Demand}

In fact, cloud administrations are apps that operate a bit of space at cloud computing establishments via internal program or even the Internet. Cloud computing empowers vendors to create, transmit and run programs that can undoubtedly be made in a restricted (flexible) manner, perform quickly (execution) and never crash and burn (relentless quality) (or, if nothing else so often)

\section{a. Availability}

In reality, its objective of simplicity for cloud computing systems (counting applications as well as establishments) is to ensure that its customers can make use of them at any level, at any place. Cloud computing system allows its customers to enter the platform (e.g., services, administrations) from anywhere as the cloud community characteristics of its. This is true for all systems in the cloud infrastructure (e.g., IaaS, PaaS, SaaS, DaaS, and therefore on). The cloud computing program would evacuate all of the optimal open entrance for each of the customers (state it is adaptable for any number of customers) required to be reached at any point.

\section{b. Confidentiality}

It suggests keeping information issues for clients within cloud structures. You'll find 2 basic philosophies (i.e., actual physical separation as well as cryptography) to achieve some security that cloud computing vendors are falling adequately.

\section{c. Data respectability}

The cloud system expects to guarantee confidentiality of details (i.e. not lost or maybe updated by unapproved customers). As information is actually the basis for offering cloud computing administrations, for example, Data as a Service, Software as a Service, Platform as a Service, it is actually a chief errand to keep information genuine.

\section{CONCLUSION}

This particular paper discussed the designing and certainly understood establishment of cloud computing. It additionally watched out for problems as well as problems of cloud computing in detail. Regardless of the handful of demands as well as the demand for more effective approaches structures, cloud computing is actually changing into an immensely engaging perspective, particularly for gigantic undertakings.

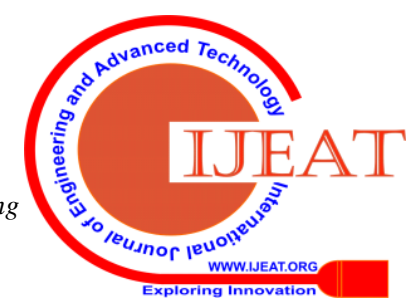




\section{Methodological Research on Architecture of Cloud Service Models in Cloud Computing}

Cloud Computing exercises might influence the undertakings within many years as it cans out and out change IT.

\section{REFERENCES}

1. T. Dillon, C. Wu, and E. Chang, "Cloud Computing: Issues and Challenges," 2010 24th IEEE International Conference on Advanced Information Networking and Applications (AINA), pp. 27-33, DOI= 20-23 April 2010.

2. M. Q. Zhou, R. Zhang, W. Xie, W. N. Qian, and A. Zhou, "Security and Privacy in Cloud Computing: A Survey," 2010 Sixth International Conference on Semantics, Knowledge and Grids(SKG), pp.105-112, DOI= 1-3 Nov. 2010.

3. J. F. Yang and Z. B. Chen, "Cloud Computing Research and Security Issues," 2010 IEEE International Conference on Computational Intelligence and Software Engineering (CiSE), Wuhan pp. 1-3, DOI= 10-12 Dec. 2010.

4. S. Zhang, S. F. Zhang, X. B. Chen, and X. Z. Huo, "Cloud Computing Research and Development Trend," In Proceedings of the 2010 Second International Conference on Future Networks (ICFN '10). IEEE Computer Society, Washington, DC, USA, pp. 93-97. DOI=10.1109/ICFN.2010. 58 .

5. J. J. Peng, X. J. Zhang, Z. Lei, B. F. Zhang, W. Zhang, and Q. Li, "Comparison of Several Cloud Computing Platforms," 2009 Second International Symposium on Information Science and Engineering (ISISE '09). IEEE Computer Society, Washington, DC, USA, pp. 23-27, DOI=10.1109/ISISE.2009.94

6. S. Zhang, S. F. Zhang, X. B. Chen, and X. Z. Huo, "The Comparison between Cloud Computing and Grid Computing," 2010 International Conference on Computer Application and System Modeling (ICCASM), pp. V11-72 - V11-75, DOI= 22-24 Oct. 2010.

7. Che, Jianhua \& Duan, Yamin \& Zhang, Tao \& Fan, Jie. (2019). Study on the Security Models and Strategies of Cloud Computing. Procedia Engineering. 23. 586-593. 10.1016/j.proeng.2011.11.2551.

8. Singh, Palvinder \& Student, M-Tech \& Jain, Anurag. (2018). Survey Paper on Cloud Computing. International Journal of Innovations in Engineering and Technology (IJIET). 3. 84-89.

9. Yan, Xiaowei \& Zhang, Xiaosong \& Chen, Ting \& Zhao, Hongtian \& $\mathrm{Li}$, Xiaoshan. (2012). The Research and Design of Cloud Computing Security Framework. Lecture Notes in Computer Science. 121. 757-763. 10.1007/978-3-642-25541-0_95.

10. $\mathrm{Tj}$, Asniar \& Budiawan, Reza. (2016). Implementation of cloud computing in higher education. IOP Conference Series: Materials $\begin{array}{llll}\text { Science } \quad \text { and } & \text { Engineering. } & 128 .\end{array}$ 10.1088/1757-899X/128/1/012022.

11. M. N. Huhns and M. P. Singh, "Service-Oriented Computing: Key Concepts and Principles," IEEE Internet Computing, vol. 09, pp. 75 81, 2005.

12. Quail MA, Smith M, Coupland P, Otto TD, Harris SR, Connor TR, et al A tale of three next generation sequencing platforms: comparison of Ion Torrent, Pacific Biosciences and IlluminaMiSeq sequencers. BMC Genomics 2012;13:341.

13. M. N. Huhns and M. P. Singh, "Service-Oriented Computing: Key Concepts and Principles," IEEE Internet Computing, vol. 09, pp. 75 81, 2005.

14. I. Foster and C. Kesselman, The Grid: Blueprint for a New Computing Infrastructure : Morgan Kaufmann, 1998.

15. J. Napper and P. Bientinesi, "Can cloud computing reach the top500?," in Combined Workshops on UnConventional High Performance Computing Workshop plus Momory Access Workshop, 2009, pp. 17-20

16. techtarget.com/definition/private-cloud.

17. ManjuSharma, Sadia Husain, Shazia Ali, International Journal of Latest Research in Science and Technology ISSN (Online):2278- 5299Volume 6, Issue 1: Page No.52-56,January-February 2017 Cloud Computing Risks And Recommendations For Security.

18. Monjur Ahmed1 and Mohammad Ashraf Hossain, Cloud Computing And Security Issues In The cloud, International Journal of Network Security \& Its Applications (IJNSA), Vol.6, No.1, January 2014

\section{AUTHORS PROFILE}

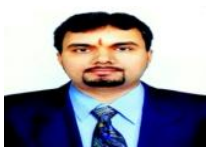

Dr. Diwakar Ramanuj Tripathi, Received the graduation (B.Sc.) degree in Computer Science, Master degree (MCA) in computer Application and Doctor of Philosophy (Ph.D.) in Computer Science. $\mathrm{He}$ is a Microsoft Certified I.T. professional (MCITP), Microsoft Certified Technology Specialist (MCTS) and
Microsoft Certified Trainer (MCT) with $10+$ years' of experience in a field of Computer Science \& Information Technologies. He has presented several research papers in various international and national level conferences and also published several research papers in various reputed international journals. He is currently working as an Information Technology Consultant in Nagpur (Maharashtra).

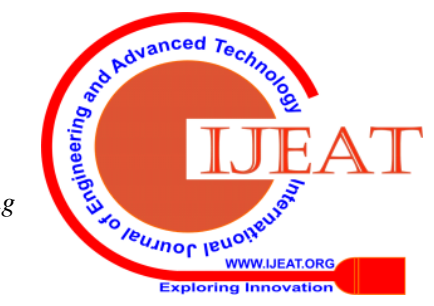

